\title{
Head and Eye Movements in Unrestrained Pigeons (Columba livia)
}

\author{
Andreas Wohlschläger, Ralf Jäger, and Juan D. Delius
}

\begin{abstract}
Head and eye movements were simultaneously recorded during locomotory and pecking behavior of 4 pigeons (Columba livia), which were trained to traverse a conditioning chamber, with a pecking key and a food dispenser at each end. Each trial involved key pecking, walking, and feeding. Head movements were registered with a skull-mounted miniature accelerometer, and eye movements were recorded with implanted electrooculographic electrodes. An almost perfect temporal coordination between head and eye movements was observed during both walking and feeding bouts. During walking, head movements primarily provide retinal image stability, and eye movements support visual scanning. During feeding, head movements mainly subserve the grasping of food items, and eye movements maintain visual fixation on them. Because the eyes are reflexively closed during the middle phase of pecks, the head and eye movements are then under ballistic control.
\end{abstract}

The peculiar saltatory head motions that many birds exhibit while they walk have repeatedly attracted interest in the past. As early as 1930, Dunlap and Mowrer reported that although the body of locomoting chickens, pigeons, and starlings moves forward relatively smoothly, the head is held still and only thrust forward at intervals. This implies a succession of rapid forward and slower backward movements of the head with respect to the body. Some authors have also drawn attention to a coordination between leg stepping and head bobbing (Bangert, 1960; Daanje, 1951). A related gazestabilizing response, that is, head nystagmus, occurs when these birds are exposed to a rotating visual environment (Fite, 1968; Frost, 1978; Fukuda, 1951; Gioanni, 1988a; Simon, 1954). A purely vestibularly driven head nystagmus has been demonstrated in pigeons (Gioanni, 1988b; Huizinga \& Meulen, 1951). However, Friedman (1975b) and Frost (1978) have concluded after examining the head motions of doves and pigeons in various experimental situations that the retinal image slip associated with locomotion is the principal stimulus that steers the rhythmic head bobbing (see also Davies \& Green, 1988).

These movements are so prominent that the occurrence of eye movements in birds was virtually overlooked for a long time. Although Benjamins and Huizinga (1927), and later Nye (1968), noted the presence of eye movements in pigeons, such movements have only been described in any detail during the past decade. It is now well established that the movements can amount to $20^{\circ}$ or more, particularly in the hori-

Andreas Wohlschläger, Ralf Jäger, and Juan D. Delius, Allgemeine Psychologie, Universität Konstanz, Konstanz, Federal Republic of Germany.

This research was supported by a grant from the Deutsche Forschungsgemeinschaft.

We thank W. Hörster and O. Güntürkün, who read a draft and offered comments, Julia Delius, who revised the English, and A. Niemuth, who helped much with the preparation of the article.

Correspondence concerning this article should be addressed to Juan D. Delius, Allgemeine Psychologie, Universität Konstanz, D-7750 Konstanz, Federal Republic of Germany. zontal, nasotemporal plane (Bloch, Martinoya, \& Rivaud, 1981). Pigeons show clear ocular nystagmic responses in conjunction with collic nystagmic movements (Gioanni, 1988a, 1988b; Gioanni, Rey, Villalobos, Bouyer, \& Gioanni, 1981). An understanding of pigeon eye movements is complicated by the fact that these birds feature two distinct, highresolution retinal areas, a fovea centralis and an area dorsalis (Emmerton, 1983; Galifret, 1968; see also Kirmse, 1990). Both Bloch, Rivaud, and Martinoya (1984) and Martinoya, LeHouezec, and Bloch (1984) have suggested that these areas are connected with different modes of viewing: respectively, a lateral monocular one, associated with conjugate, disjugate, or independent eye movements, and a frontal binocular fixation, associated with either convergent or divergent eye movements.

Few studies have been concerned with the coordination of head and eye movements in pigeons. During a detailed study with the search coil method, Gioanni (1988a) observed a nearly perfect synchronization of rotational, optokinetically triggered head and eye saccades in restrained pigeons. Bloch, Jäger, Lemeignan, and Martinoya (1988), using electrooculographic (EOG) and videographic techniques on freely foraging pigeons, reported very briefly that they observed ocular saccades only during head thrusts but not when the head was held stationary in space.

Because the knowledge about the relations between normal head and eye movements of unrestrained pigeons is still very incomplete, we now report a detailed qualitative and quantitative investigation of the nature, extent, frequency, and coordination of these movements in a quasi-ecological situation that involves walking and feeding. The discussion of the results takes into account the findings of previous research and, to some extent, the comparative distribution and the probable functions of oculocollic movements in birds.

Eye rotations were measured with the EOG, and head motions were registered with an accelerometer (Siemann \& Delius, 1992), which allows a higher temporal resolution than the 25 frames/second videography used by Bloch and collaborators (Bloch et al., 1984; Bloch et al., 1988; Martinoya et al., 1984) and which does not impose as much 


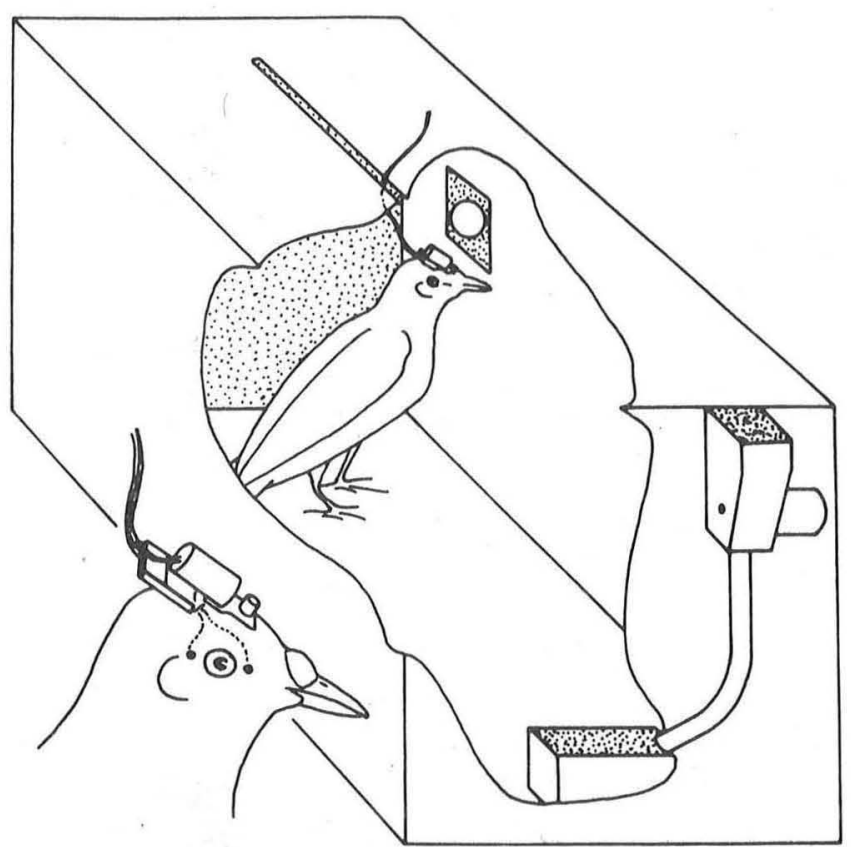

Figure 1. Experimental chamber as used during the final experimental session. (Insert shows a pigeon's head with the electrooculographic and accelerometric setup.)

movement constraint as the search coil technique used by Gioanni (1988a, 1988b).

\section{Method}

Four homing pigeons (Columba livia) served as subjects. They were housed in individual cages and kept deprived to $90 \%$ of their normal weight throughout the experiment. The apparatus consisted of an elongated conditioning chamber $(82 \mathrm{~cm}$ wide $\times 45 \mathrm{~cm}$ high $\times 43 \mathrm{~cm}$ deep). A back-illuminated, translucent pecking key was located in one corner. A specially designed solenoid dispenser issued 5-10 grains of milo into a trough when activated. It was initially placed next to the key but finally placed at the opposite end of the chamber (Figure 1). Events were controlled and registered by modular digital equipment (Coulbourn, Allentown, PA). The pigeons' behavior was monitored with closed-circuit television.

With the food dispenser in the initial position, the subjects were first conditioned to peck the key during 5 daily sessions of 100 autoshaping trials (Delius, 1983). During 10 subsequent instrumental conditioning sessions, the dispenser was gradually moved away from the key and the number of pecks required for food delivery was raised to two. All pigeons performed steadily and completed the 100-trial sessions about 30 min before they underwent surgery.

For the operation the pigeons were anesthetized with a pentobarbital-chloral-hydrate mixture (Mallin \& Delius, 1983) and their head placed in a stereotaxic holder. The scalp was incised and retracted. Small cavities were drilled posteriorly and anteriorly into the left bony orbital arch and into the left occipital cranial bone (Figure 1). The cavities received two ocular electrodes and a reference electrode. These were Teflon-coated silver wires with chlorinated ball tips ( $1 \mathrm{~mm}$ in diameter) surrounded by paper collars that were glued to the bone surface. The electrodes lead to a miniature connector cemented to the skull together with an aluminium block $(3.5 \times 1.5 \times 6.0 \mathrm{~mm})$. The block served to screw on the accel- erometer (Piezotronics, Depew, NY) with its front end about $30^{\circ}$ above the eye center-beak tip plane (Figure 1). The total weight of the arrangement was less than $5 \mathrm{~g}$. Siemann and Delius (1992) showed that such load has an insignificant effect on head motions.

After recovery the pigeons were retrained with 3 daily familiarization sessions with the electrodes and accelerometer connected through elastically suspended, lightweight cables to the recording equipment. The accelerometer and EOG signals were fed into, respectively, alternating- and direct-current amplifiers and low-pass filtered $(200 \mathrm{~Hz}$; Neurolog, Welwyn Garden City, United Kingdom). Sample traces were stored and displayed on a digital oscilloscope (Siemens, Munich, FRG) for detailed inspection. A fourth and final session served to acquire the EOG and accelerometer data for detailed analysis. The signals from several trials randomly selected from the middle of the session were stored with an instrumentation tape recorder (Teac, Montebello, CA). Recording began with the second key peck of a given trial and ended with the first key peck of the following trial. Each of these trials lasted between 15 and $20 \mathrm{~s}$.

For EOG calibration the head of each pigeon was held fixed by the head block with the beak pointing $30^{\circ}$ below the horizontal plane (modal head posture of pigeons; Erichsen, Hodos, Evinger, Bessette, \& Phillips, 1989). Left eye and the EOG trace was simultaneously videographed for $200 \mathrm{~s}$. Pupil translations and EOG deflections were measured on the monitor screen. The angular rotation $a$ during saccades was derived according to $a=\arcsin (l \div$ $r$ ), where $l$ was the scaled pupil translations and $r$ was the rotational radius of the pupil from Marshall, Mellerio, and Palmer's (1973) schematic pigeon eye. EOG amplitudes correlated best $(r=.99)$ with the angular rotation components along a plane $11^{\circ}$ nasally below the horizontal plane with a sensitivity of $56 \pm 6 \mu \mathrm{V} /$ degree. Most larger saccades actually coursed along approximately the same plane (Figure 2; compare also Gioanni, 1988a; Lemeignan, Sansonetti, \& Gioanni, 1992). The nasotemporal electrode arrangement was inevitably less sensitive for the infrequent and smaller movements in other directions.

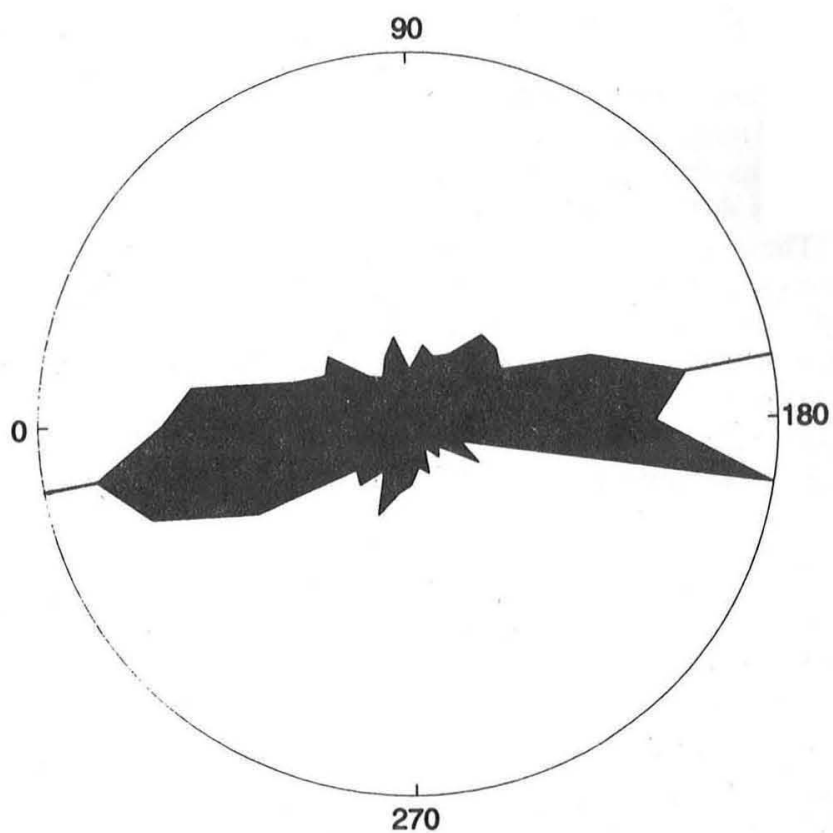

Figure 2. Saccade direction distribution during the calibration session (4 pigeons). (Line indicates the modal orientation of the saccades. $0^{\circ}-180^{\circ}$ : anterior-posterior horizontal plane.) 
Tests with the unidirectional accelerometer attached to either an adjustable frequency pendulum or to a vertical disc rotating at controlled speeds showed the manufacturer's calibrations (main axis sensitivity of $0.55 \mathrm{mV} /\left[\mathrm{m} / \mathrm{s}^{2}\right]$, across sensitivity of less than $5 \%$, from $5 \mathrm{~Hz}$ to $10 \mathrm{kHz}$ ) to be accurate. However, the accelerometer records are not a precise reflection of the forward-backward movements of the pigeon head. This is because the transducer has no direct-current response and is affected by terrestrial gravity as its orientation changes in relation to the horizontal. It is also cosine driven by accelerations oblique to the main axis and is weakly sensitive to centrifugal accelerations during curvilinear motions. Nevertheless, because our principal interest was in the timing of predominant anterior-posterior head movements, the characterization provided by the accelerometer signals was sufficient for our purposes. With a few realistic assumptions, it was even possible to compute approximate velocity and position estimates (Wohlschläger, 1991).

Selected sections of the taped EOG and accelerometer signals were digitized at a $1000-\mathrm{Hz}$ sampling rate with a personal computer. The EOG values were converted to angular degrees, and the accelerometer values to acceleration in meters per seconds squared and stored on disk with a common timing code for later analysis.

\section{Results}

Each trial involved three behavioral segments: approaching the dispenser trough, eating grains, and returning to the pecking key. Inspection of the accelerometer and EOG raw data graphs allowed a straightforward identification of these components. Figure 3 shows the course of a typical trial. The accelerometer trace begins with two negative-positive acceleration waves that represent back movements of the head after the final key contact. A sequence of positive-negative acceleration waves, most of which reflect forward head thrusts that accompany the pigeons' progress toward the trough and a few associated with scanning movements while the pigeons stand still, characterized the approach phase. The intervening passages in which the head remained stationary in space are also easily recognized. The final pair of larger positive-negative waves reflect head thrusts that precede prepeck fixations (Goodale, 1983). The eating phase is marked by a series of small, positive and large, brief, negative acceleration peaks. The latter identify the forward deceleration on beak-substrate impact and are followed by a backward acceleration that initiates head elevation. The rapid accelerometer oscillations after most of these pecks represent mandibulatory repositioning and transport head jerks that precede the swallowing of grain. Their absence signals a failure to grasp a grain (Siemann \& Delius, 1992). Occasional smaller amplitude positive-negative acceleration waves that follow are mostly prefixation head thrusts, which herald the next peck. The return walk to the key is initiated by a backward head jerk, out of the trough (negative-positive accelerations), followed by a renewed series of forward head bobs (positive-negative accelerations) associated with walking.

The EOG trace also exhibited a different pattern according to whether pigeons walked or fed. During walking, pigeons produced large nasal or temporal saccades, which terminated in maintained eye deflections off the resting position. However, shortly before and throughout eating, birds moved and held their eyes in a nasally deflected position. A series of smaller amplitude nasal and temporal saccades were superimposed on this basic eye position. A large temporal saccade closed the eating phase.

Head stationarity was assumed whenever the acceleration was less than $3 \mathrm{~m} / \mathrm{s}^{2}$ for at least 20 consecutive ms (Figure 4). Values outside these criteria were classified as head motion. EOG sections were classed as saccades if coincidentally the eye position difference from one plateau to the next exceeded $1^{\circ}$ (a rather low criterion; cf. Bloch et al., 1984), the rotation took less than $100 \mathrm{~ms}$ to complete, and the speed of the eye movement exceeded $40 \%$ (Figure 4). Slower, smaller amplitude signals were classified as resting periods, although some may have represented minor following movements.

By these criteria, 913 head thrusts were identified within the 290-s record analyzed. Of these, 219 belonged to the

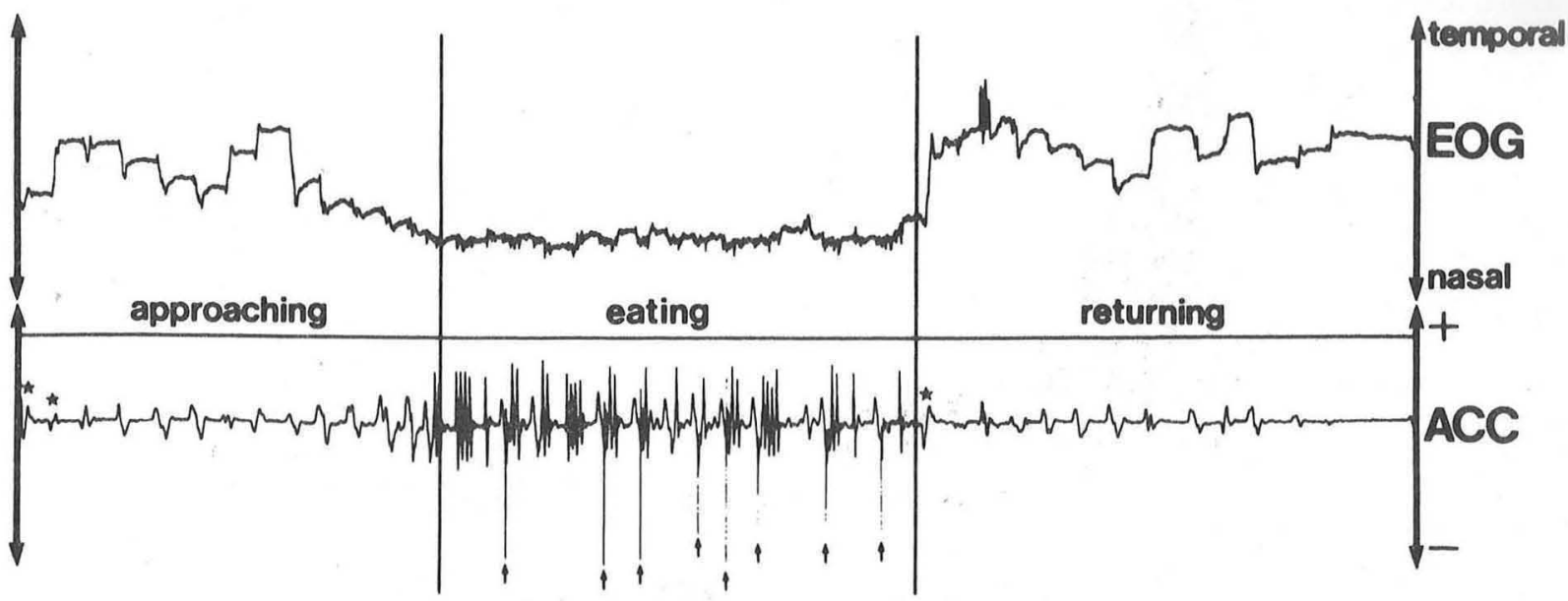

Figure 3. Head accelerations and electrooculogram traces recorded during a typical trial. (Backward head movements off the key and off the feeder are marked by asterisks. Beak-substrate impacts during pecks are marked with arrows.) 


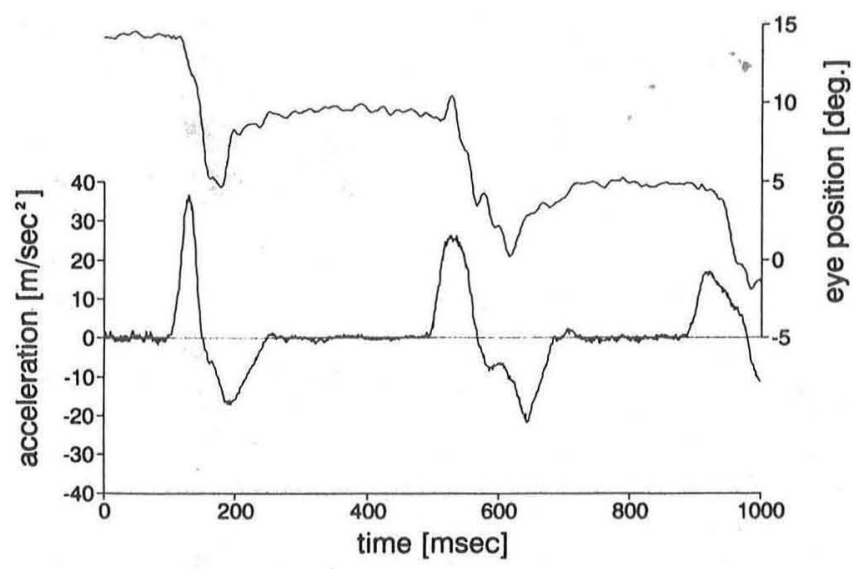

Figure 4. Sample section of head accelerations and electrooculogram during walking. (Note the synchrony of head and eye movements.)

eating sections of the record, and the remaining 694 corresponded to walking sections. The thrusts' average duration was $147.2 \mathrm{~ms}$, and their average peak acceleration $17.0 \mathrm{~m} / \mathrm{s}^{2}$; both duration and acceleration were slightly but significantly higher for the more frequent forward thrusts (548) than for the rarer backward thrusts (146). These latter probably occurred only when the pigeons stood momentarily still. Forward thrusts were estimated to be on average $55.5 \mathrm{~mm}$ long (maximum of $156 \mathrm{~mm}$ ) and backward thrusts only an average $22.7 \mathrm{~mm}$ long. The head-immobility periods lasted on average $152.8 \mathrm{~ms}$. When the eating phases were excluded from the analysis, the head thrusts lasted a mean $148.6 \mathrm{~ms}$ and the head holds, a mean $175.2 \mathrm{~ms}$.
The same 290-s record contained 3,196 eye saccades. The average eye-rotation speed during saccades was $160.0 \%$, and they lasted an average $22.8 \mathrm{~ms}$. Saccades were obviously briefer but more frequent than head movements. The intersaccade periods lasted an average $67.9 \mathrm{~ms}$. Nasal saccades were slightly more frequent $(1,688)$ but of significantly lesser average amplitude $\left(3.3^{\circ}\right)$ than temporal ones $\left(1508\right.$ and $\left.3.6^{\circ}\right)$. The biggest temporal saccade recorded subtended $24^{\circ}$ and the largest nasal one, $26^{\circ}$. Saccades during the pecking phases were of significantly lesser mean amplitude than those that occurred during the locomotion phase $\left(2.7^{\circ}\right.$ against $3.7^{\circ}$ ), but whereas the former started from, on average, a slightly temporal eye position $\left(2.7^{\circ}\right)$, the latter did so from a markedly nasal position $\left(12.4^{\circ}\right)$.

To characterize the oculocollic coordination, the data were analyzed with regard to the synchronism of eye and head motions. Three kinds of eye movements were distinguished, depending on their timing in relation to the head movements. The most frequent type were embedded saccades $(2,764$ or $86.5 \%$ ) that began and ended within the duration of a given single head thrust. Overlapping saccades, which started before a head thrust began or ended after a head thrust stopped, accounted for a further 230 (7.2\%). Because their average overlap amounted to $80.9 \%$ of their duration and they were of the same mean magnitude as embedded saccades $\left(3.5^{\circ}\right)$, overlapping saccades were pooled with these latter as synchronous saccades. The remaining $202(6.3 \%)$ eye saccades were characterized as asynchronous because they occurred wholly within head-hold periods. They were significantly smaller than the others $\left(M=2.4^{\circ}\right)$. In Figure 5, the frequency of both types of saccades is plotted against amplitude, for which synchronous ones reached up to $26^{\circ}$ and asynchronous saccades; to only $5^{\circ}$.

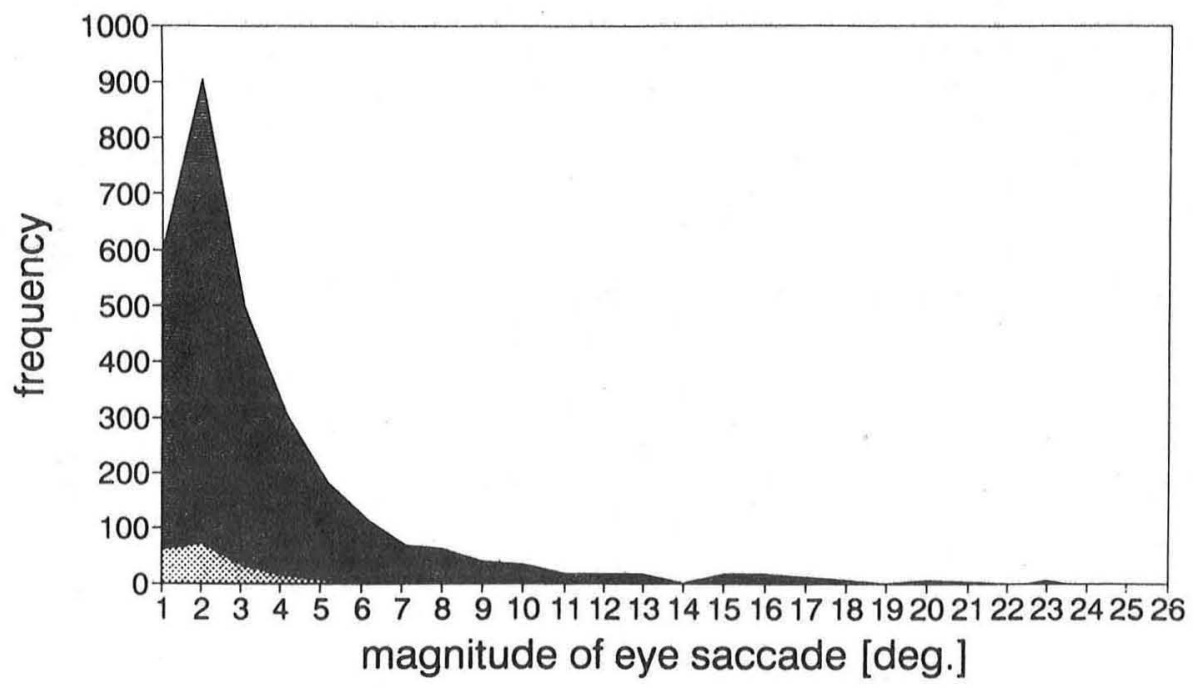

asynchronous

simultaneous

Figure 5. Simultaneous and asynchronous eye saccades frequency as a function of their angular magnitude $(3,169$ saccades from 4 pigeons). 
To examine the coordination of eye movements with the final head thrust, the instant of substrate impact was filed for each peck by screening the accelerometer data for the characteristic large negative peaks (Figure 2; Siemann \& Delius, 1992). The acceleration and EOG courses for the 219 pecks were averaged with reference to that instant. The lower panel of Figure 6 shows that the final nasal eye rotation begins from an already forward nasal position about $100 \mathrm{~ms}$ before impact as the head is thrust forward, reaches the most forward position slightly before beak impact, and returns to about baseline position some $150 \mathrm{~ms}$ later with divergent eye movements accompanying the head-lifting and grain-positioning movements. Because averaging has a smoothing effect, the course of an exemplary single peck is separately illustrated for comparison in the upper panel of Figure 6. Pigeons habitually close their eyes shortly before substrate impact (verified in our video records), as a protective reflex against particle backscatter (Delius, 1985). The timing of eye closure and opening, very precisely measured by Zeigler, Levitt, and Levine (1980) with high speed cinematography, is inserted in the graphs in Figure 6. It is patent that the final eye and head movements are only completed when meaningful visual input is already absent.
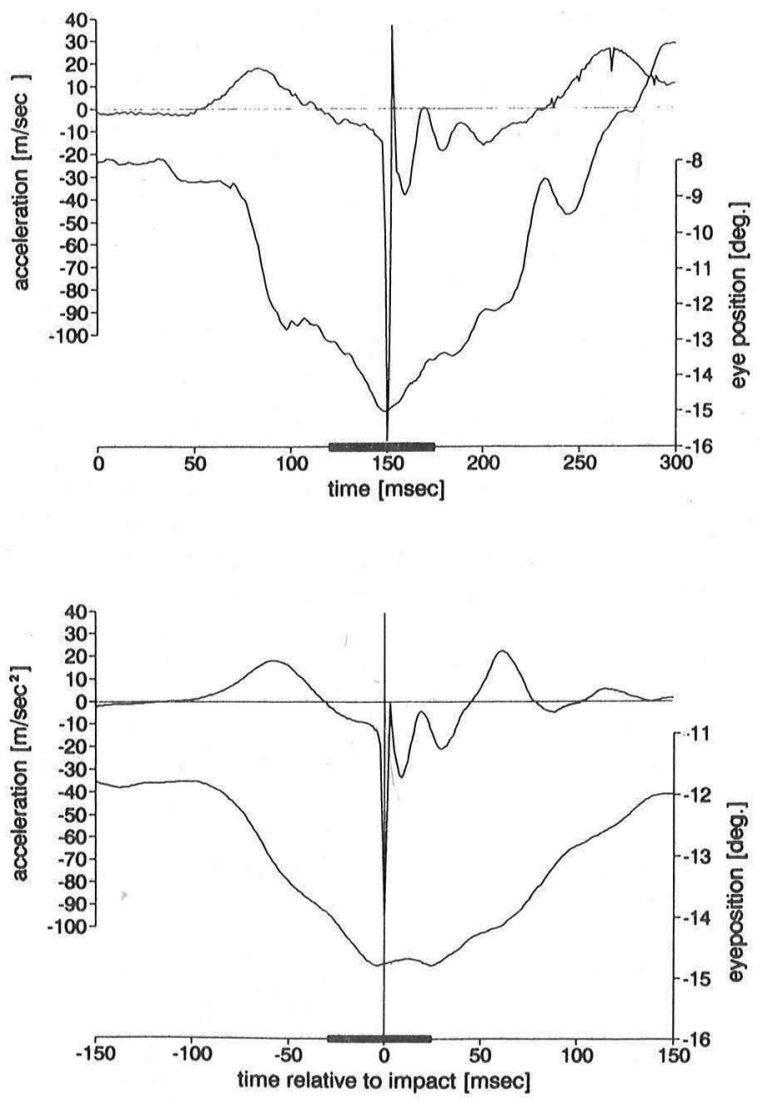

Figure 6. Head acceleration (upper trace) and electrooculogram (lower trace) before and after substrate impact during a single peck (upper panel) and head acceleration (upper trace) and electrooculogram (lower trace) before and after substrate impact averaged over 219 pecks of 4 pigeons (lower panel). (Eye closure is indicated by the heavy horizontal bar.)

\section{Discussion}

The head bobbing shown by pigeons while they walk reveals itself as a series of forward head accelerationdeceleration waves. Average peak head speeds were reckoned to be of the order of $63 \mathrm{~cm} / \mathrm{s}$. The head was assessed to be stationary for $54.2 \%$ of the total locomotion time (comparable with Bangert's, 1960, cinematographic data for baby chickens). The eye saccades that were quite variable in amplitude (typical speed about $160 \%$ s) always accompanied the head movements. Several saccades could occur in conjunction with a single collic movement. Only $6 \%$ of the eye movements occurred when the head was stationary.

With the present information and that provided by other authors (especially Bloch et al., 1988; Bloch et al., 1984; Davies \& Green, 1988; Frost, 1978; Gioanni, 1988a; Lemeignan et al., 1992; Martinoya et al., 1984), it can be asserted that pigeons' head motions while walking have the characteristics of an optocollic nystagmus. The patterns of head motions are reflexively controlled mainly by the retinal slip caused by the forging ahead of the body. They effectively ensure a stabilization of the retinal image when the head remains spatially stationary over the advancing body. Small, slow eye movements independent of forward head jerks may occasionally supplement the stabilization. Our EOG records, by the way, represent these eye movements as saccades but that may be an artifact. Smaller optokinetic following movements often also appear to be saccadic when EOG recorded (Gioanni et al., 1981) but reveal themselves as perfectly smooth when registered with the search coil technique (Gioanni, 1988a). Avian EOGs are prone to contamination by potentials that spread from ocular muscles and by nictitating membrane potentials that mimic miniature saccades (E. Korzeniewska, personal communication, January 1988). As to the importance of static retinal images during the hold phase of the bobbing cycle, Kalveram and Merz (1976) argued convincingly that they aid the detection of small stationary features, such as seeds, or larger moving objects, such as predators, against textured backgrounds. Conversely, however, Davies and Green (1988) suggested that detection of grainlike features may be aided by the retinal image motion that accompanies forward head thrusts.

It must also be during this holding phase that the pigeon visual system selects the target for the next fixation. These fast and often large movements are carried out in synchronism with the forward head thrusts. That precludes any visual feedback control and thus defines the movements as true saccades. The saccades of either eye, though temporally linked, are largely, if not completely, independent in terms of direction and amplitude, to the extent that one eye often moves alone (Bloch et al., 1988; see also Wallman, Turkel, \& Eastzer, 1977). A small fraction of the backward saccades may be coordinated as to maintain fixation by compensating the retinal image shift due to forward head thrusts. It is reasonable to assume that most of the saccades serve to monocularly fixate visual features with either the fovea centralis when the features are laterally located and further away or with the area dorsalis when the features are more medially located and closer by (Bloch et al., 1988; Friedman, 1975a). 
When, however, binocular vision becomes important, as during food pecking, then the between-eyes coordination becomes strict and produces either convergent or divergent but always closely symmetric movements, even when one eye is experimentally occluded (Bloch et al., 1984). The initial converging saccades must serve to bring the area dorsalis into its binocular position, increasing the visual field overlap that can support true stereoscopic vision (McFadden \& Wild, 1986; Nalbach, Wolff-Oberhollenzer, \& Kirschfeld, 1990). Just before the first peck approach begins, a series of small forward saccades brings the eyes into an anterior position that is then retained during the pecking bout. Each peck within the bout is then associated with first forward saccades and then backward saccades, all of rather small amplitude. An interesting detail is that the final convergent saccade before substrate impact regularly terminates when the pigeon has already closed its eyes. This movement is therefore visually ballistic and an incidental by-product of the strong headthrust and eye-saccade linkage stressed earlier. The ballistic characteristic also applies to the final head lunge and jaw opening that nevertheless yields a precise grasping of grains (LaMon \& Zeigler, 1984; Levine \& Zeigler, 1981; Zeigler et al., 1980). During eating, in contrast to walking, head movements are clearly not under reflexive, optokinetic control. In fact, head and eyes reverse their roles. The head movements must be steered by mechanisms that ensure grain pick-up with the beak tips, whereas eye movements appear to reflexively compensate the retinal slip produced by head descent and ascent, as to maintain a binocular, frontal fixation (Martinoya et al., 1984).

It is not yet possible to define accurately what head and eye movements pigeons perform when they are standing still. Gioanni's (1988a) findings under whole-field optokinetic stimulation are difficult to transpose to an ecologically relevant situation, but they establish that stationary pigeons can show following as well as saccadic movements with both head and eyes. Our observations in the present setting, limited as they are, tend to agree, but they allow no further precision. Although taking-off and flying pigeons do not show head bobbing (Rothe \& Nachtigall, 1987), nothing is known about eye movements. In this context pigeons' visual system may be more occupied with optic flow analysis than with static pattern recognition (Martinoya \& Delius, 1990; Wang \& Frost, 1992). However, Davies and Green (1988), differing with Frost (1978), reported that during landing, pigeons exhibit an incomplete head bobbing that does not achieve head stationarity, but again they say nothing about eye movements.

The preceding account, though by no means complete, documents a remarkably variable oculocollic behavior in pigeons. The variety increases when one begins to consider the head and eye movements of other, even if less comprehensively investigated, avian species. Several of them (e.g., ducks and gulls) simply do not show head bobbing during walking, and some (e.g., sparrows) replace bobbing by hopping (Davies \& Green, 1988; Dunlap \& Mowrer, 1930; Friedman, 1975b; Whiteside, 1966), just to give some striking examples. A recent comparative overview of visuomotor behavior in birds (Kirmse, 1990) mentions further visuocol- lic response patterns that differ in other, even if less drastic, ways from those shown by pigeons. There is little relevant information about eye movements, though. However, a study on just two species (little eagle and tawny frogmouth; Wallman \& Pettigrew, 1985), which found striking differences in saccade frequency and saccade coordination, indicated that oculomotoric peculiarities are likely to contribute to the heterogenity. Fast oscillatory eye saccades that subserve vegetative rather than visual functions complicate matters further (Pettigrew, Wallman, \& Wildsoet, 1990). In view of that, any meaningful comparative analysis will have to await the availability of reasonably complete data sets for several avian species.

It may be obvious by now, however, that the oculocollic behavior of pigeons differs quite markedly from that of the best-studied species, our own. Differently from pigeons, humans normally do not exhibit head bobbing, their ocular saccades are virtually always conjugate, and their convergentdivergent eye adjustments are rarely saccadic (Gouras, 1985). Among the better studied mammals, it is rabbits, if anything, that are vaguely reminiscent of pigeons, in that they have predominantly saccadic eye movements often linked to head movements and frequently leading to frontal binocular fixation, perhaps a faint evolutionary convergence due to their also lateral positioning of the eyes (Collewijn, 1977; Zuidam \& Collewijn, 1979). More generally, it may be that the oculocollic behavior of animals is phylogenetically rather adaptable and not as much constrained by phyletic relations as is sometimes assumed.

\section{References}

Bangert, H. (1960). Untersuchungen zur Koordination der Kopf- und Beinbewegungen beim Haushuhn [Investigations on the coordination of head and leg movements of chickens]. Zeitschrift für Tierpsychologie, 17, 143-164.

Benjamins, C. E., \& Huizinga, E. (1927). Untersuchungen über die Funktion des Vestibularapparates bei der Taube [Investigations on the functions of the vestibular apparatus of the pigeon]. Pflügers Archiv der gesamten Physiologie, 217, 105-123.

Bloch, S., Jäger, R., Lemeignan, M., \& Martinoya, C. (1988). Correlation between ocular saccades and head movements in walking pigeons. Journal of Physiology, 406, 173P.

Bloch, S., Martinoya, C., \& Rivaud, S. (1981). Eye movements in pigeons: Participation in binocular fixation and visual pursuit. Journal of Physiology, 320, 20P-21P.

Bloch, S., Rivaud, S., \& Martinoya, C. (1984). Comparing frontal and lateral viewing in the pigeon: III. Different patterns of eye movements for binocular and monocular fixation. Behavioral Brain Research, 13, 173-182.

Collewijn, H. (1977). Eye and head movements in freely moving rabbits. Journal of Physiology, 266, 471-498.

Daanje, A. (1951). On locomotory movements in birds and the intention movements derived from them. Behaviour, 3, 48-96.

Davies, M. N. O., \& Green, P. R. (1988). Head-bobbing during walking, running and flying: Relative motion perception in the pigeon. Journal of Experimental Biology, 138, 71-91

Delius, J. D. (1983). Learning. In M. Abs (Ed.), Physiology and behaviour of the pigeon (pp. 327-355). London: Academic Press. Delius, J. D. (1985). The pecking of the pigeon: Free for all. In C. F. Lowe, M. Richelle, D. E. Blackman, \& C. M. Bradshaw (Eds.), 
Behaviour analysis and contemporary psychology (pp. 53-81). Hillsdale, NJ: Erlbaum.

Dunlap, K., \& Mowrer, O. H. (1930). Head movements and eye functions of birds. Journal of Comparative Psychology, 12, 99112.

Emmerton, J. (1983). Vision. In M. Abs (Ed.), Physiology and behaviour of the pigeon (pp. 245-266). London: Academic Press.

Erichsen, J. T., Hodos, W., Evinger, C., Bessette, B. B., \& Phillips, S. J. (1989). Head orientation in pigeons: Postural, locomotor and visual determinants. Brain, Behavior and Evolution, 33, 268278.

Fite, K. V. (1968). Two types of optomotor response in the pigeon Journal of Comparative and Physiological Psychology, 66, 308314.

Friedman, M. B. (1975a). How birds use their eyes. In P. Wright, P. Caryl, \& D. M. Vowles (Eds.), Neural and endocrine aspects of behaviour in birds (pp. 182-204). Amsterdam: Elsevier.

Friedman, M. B. (1975b). Visual control of head movements during avian locomotion. Nature, 255, 67-69.

Frost, B. J. (1978). The optokinetic basis of head-bobbing in the pigeon. Journal of Experimental Biology, 74, 187-195.

Fukuda, T. (1951). The unidirectionality of the labyrinthine reflex in relation to the unidirectionality of the optokinetic reflex. Acta Otolaryngologica, 50, 507-516.

Galifret, Y. (1968). Les diverses aires fonctionelles de la rétine du pigeon [The various functional areas of the retina of the pigeon]. Zeitschrift für Zellforschung, 86, 535-545.

Gioanni, H. (1988a). Stabilizing gaze reflexes in the pigeon (Columba livia): I. Horizontal and vertical optokinetic eye $(\mathrm{OKN})$ and head (OCR) reflexes. Experimental Brain Research, $69,567-582$.

Gioanni, H. (1988b). Stabilizing gaze reflexes in the pigeon (Columba livia): II. Vestibulo-ocular (VOR) and vestibulo-collic (closed loop VCR) reflexes. Experimental Brain Research, 69, 583-593.

Gioanni, H., Rey, J., Villalobos, J., Bouyer, J. J., \& Gioanni, Y (1981). Optokinetic nystagmus in the pigeon (Columba livia): I Study in monocular and binocular vision. Experimental Brain Research, 44, 362-370.

Goodale, M. A. (1983). Visually guided pecking in the pigeon (Columba livia). Brain, Behavior and Evolution, 22, 22-41.

Gouras, P. (1985). Oculomotor system. In E. R. Kandel \& J. H. Schwartz (Eds.), Principles of neural science (pp. 571-583). New York: Elsevier.

Huizinga, E., \& Meulen, P. van der. (1951). Vestibular rotatory and opto-kinetic reactions in pigeon. Brain Research, 60, 927-947.

Kalveram, K. T., \& Merz, F. (1976). Über die Unterscheidung zwischen Eigenem und Fremdem oder Warum Hühner beim Laufen mit dem Kopf nicken [The distinction between own and foreign, or why chickens bob their head while walking]. Psychologische Beiträge, 18, 135-142.

Kirmse, W. (1990). Kritische Übersicht zur selektiven Sensomotorik des Blickens und multifoveates Spähen bei Vögeln [Critical review of the sensomotorics of selective viewing and multifoveate gazing in birds]. Zoologisches Jahrbuch der Physiologie, 94, 217-228.

LaMon, B., \& Zeigler, H. P. (1984). Grasping in the pigeon: Stimulus control during conditioned and consummatory responses. Animal Learning \& Behavior, 12, 223-231.

Lemeignan, M., Sansonetti, A., \& Gioanni, H. (1992). Spontaneous saccades under different visual conditions in the pigeon. $\mathrm{Neu}$ roreport, 3, 17-20.
Levine, R. R., \& Zeigler, H. P. (1981). Extratelencephalic pathways and feeding behavior in the pigeon (Columba livia). Brain, Behavior and Evolution, 19, 56-92.

Mallin, H. D., \& Delius, J. D. (1983). Inter- and intraocular transfer of color discriminations with mandibulation as an operant in the head-fixed pigeon. Behaviour Analysis Letters, 3, 297-309.

Marshall, J., Mellerio, J., \& Palmer, D. A. (1973). A schematic eye for the pigeon. Vision Research, 13, 2449-2453.

Martinoya, C., \& Delius, J. D. (1990). Perception of rotating spiral patterns by pigeons. Biological Cybernetics, 63, 127-134.

Martinoya, C., LeHouezec, J., \& Bloch, S. (1984). Pigeon's eyes converge during feeding: Evidence for frontal binocular fixation in a lateral-eyed bird. Neuroscience Letters, 45, 335-339.

McFadden, S., \& Wild, M. J. (1986). Binocular depth perception in the pigeon. Journal of the Experimental Analysis of Behavior, 45, 149-160.

Nalbach, H. O., Wolf-Oberhollenzer, F., \& Kirschfeld, K. (1990). The pigeon's eye viewed through an ophthalmoscopic microscope: Orientation of retinal landmarks and significance of eye movements. Vision Research, 30, 529-540.

Nye, P. W. (1968). The monocular eye movements of the pigeon. Vision Research, 9, 133-147.

Pettigrew, J. D., Wallman, J., \& Wildsoet, C. F. (1990). Saccadic oscillations facilitate ocular perfusion from the avian pecten. $\mathrm{Na}$ ture, 343, 362-363.

Rothe, H. J., \& Nachtigall, W. (1987). Pigeon flight in a wind tunnel: I. Aspects of wind tunnel design, training methods and flight behaviour of different pigeon races. Journal of Comparative Physiology B, 157, 91-98.

Siemann, M., \& Delius, J. D. (1992). The variability of forage pecking in pigeons. Ethology, 92, 29-50.

Simon, M. E. (1954). Der optomotorische Nystagmus während der Entwicklung normaler und optisch isoliert aufgewachsener Küken [The optomotor nystagmus during the development of normal and visually isolated chicks]. Zeitschrift für vergleichende Physiologie, 37, 82-105

Wallman, J., \& Pettigrew, J. D. (1985). Conjugate and disjunctive saccades in two avian species with contrasting oculomotor strategies. Journal of Neuroscience, 5, 1418-1428.

Wallman, J., Turkel, J., \& Eastzer, D. H. (1977). Interactions between the eyes in optokinetic nystagmus of chickens. Neuroscience Abstracts, 3, 158

Wang, Y., \& Frost, B. J. (1992). Time to collision is signalled by neurons in the nucleus rotundus of pigeons. Nature, 356, 236238

Whiteside, T. C. D. (1966). The head movements of walking birds. Journal of Physiology, 181, 31P-32P.

Wohlschläger, A. (1991). Koordination von Kopf- und Augenbewegungen bei Tauben [Coordination of head and eye movements in pigeons]. Diploma thesis, Universität Konstanz, Konstanz, FRG.

Zeigler, H. P., Levitt, P. W., \& Levine, R. R. (1980). Eating in the pigeon (Columba livia): Movement patterns, stereotypy, and stimulus control. Journal of Comparative and Physiological Psychology, 94, 783-794.

Zuidam, I., \& Collewijn, H. (1979). Vergence eye movements of the rabbit in visuomotor behavior. Vision Research, 19, 185-194. 